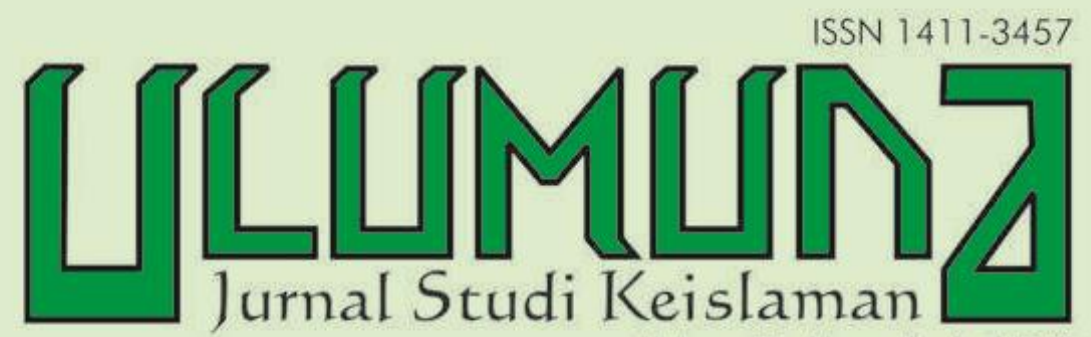

Volume $17 \cdot$ Nomor $1 \cdot$ Juni 2013

TERAKREDITASI B: SK Dirjen Dikti Kemdikbud Nomor: 56/DIKTI/Kep/2012, Tanggal 24 Juli 2012

MENCERNA AKAR FILSAFAT DALAM ISLAM Ismail Fahmi Arrauf PERKEMBANGAN PARADIGMA EPISTEMOLOGI DALAM FILSAFAT ISLAM Fathul Mufid EPISTEMOLOGI ISLAM: KEDUDUKAN WAHYU SEBAGAI SUMBER ILMU Anwar Muiahidin DARI ISLAMISASI ILMU MENUJU PENGILMUAN ISLAM: MELAWAN HEGEMONI EPISTEMOLOGI BARAT Ismail Toib dan Mukhlis INDUKTIVISME SEBAGAI BASIS PENGEMBANGAN ILMU PENGETAHUAN DALAM ISLAM Masdar Hilmy

PERTAUTAN ONTOLOGI FILSAFAT DAN TASAWUF: PERSPEKTIF TENTANG RELASI TUHAN, MANUSIA, DAN ALAM Hadarah Rajab PERTAUTAN EPISTEMOLOGI FILSAFAT DAN TASAWUF: TELAAH SISTEM PEMIKIRAN ABDUL HALIM MAHMUD Lalu Muchsin Effendi ETIKA DALAM FILSAFAT ISLAN:

PEMIKIRAN FILOSOF MUSLIM TENTANG KEBAHAGIAAN Mustain PEngembangan Sumber Daya MANusia DALAM PERSPEKTIF EPESTIMOLOGI FILSAFAT ISLAM Asep Kumiawan 


\section{DAFTAR ISI}

\section{Pedoman Transliterasi}

1-18 • Ismail Fahmi Arrauf,

"Mencerna Akar Filsafat dalam Islam"

19-40 • Fathul Mufid,

"Perkembangan Paradigma Epistemologi

dalam Filsafat Islam"

41-64 • Anwar Mujahidin

"Epistemologi Islam:

Kedudukan Wahyu Sebagai Sumber Ilmu"

65-96 • Ismail Toib dan Mukhlis

"Dari Islamisasi Ilmu Menuju Pengilmuan Islam:

Melawan Hegemoni Epistemologi Barat"

97-126 • Masdar Hilmy

"Induktivisme Sebagai Basis Pengembangan

Ilmu Pengetahuan dalam Islam"

127-152 • Hadarah Rajab

"Pertautan Ontologi Filsafat dan Tasawuf:

Telaah Relasi Tuhan, Manusia, dan Alam"

153-190 • Lalu Muchsin Effendi

"Pertautan Epistemologi Filsafat dan Tasawuf:

Telaah Sistem Pemikiran Abdul Halim Mahmud"

191-212• Mustain

"Etika dan Ajaran Moral Filsafat Islam:

Pemikiran Para Filosof Muslim tentang Kebahagiaan"

\section{3-230 • Asep Kurniawan}

Pengembangan Sumber Daya Manusia

dalam Perspektif Epestimologi Filsafat Islam

\section{APENDIKS}




\section{PEDOMAN TRANSLITERASI}

\begin{tabular}{|c|c|c|c|c|c|c|}
\hline 1 & $=$ & $\mathbf{a}$ & $\dot{\varepsilon}$ & $\dot{\varepsilon}$ & $=$ & $\mathrm{g}$ \\
\hline ب & $=$ & b & & ف & $=$ & $\mathrm{f}$ \\
\hline 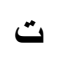 & $=$ & $\mathrm{t}$ & & ق & $=$ & $q$ \\
\hline$\dot{H}$ & $=$ & th & & ك5 & $=$ & $\mathbf{k}$ \\
\hline ج & $=$ & $\mathfrak{j}$ & & J & $=$ & 1 \\
\hline$\tau$ & $=$ & h & & م & $=$ & $\mathrm{m}$ \\
\hline$\dot{\tau}$ & $=$ & $\mathbf{k h}$ & & ن & $=$ & $\mathbf{n}$ \\
\hline د & $=$ & d & & و & $=$ & $\mathbf{w}$ \\
\hline j & $=$ & dh & 。 & 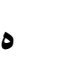 & $=$ & $\mathbf{h}$ \\
\hline J & $=$ & $\mathbf{r}$ & & $\varepsilon$ & $=$ & , \\
\hline j & $=$ & $\mathrm{z}$ & & ي & $=$ & $\mathbf{y}$ \\
\hline س & $=$ & $\mathrm{s}$ & & & & \\
\hline 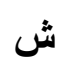 & $=$ & sh & \multicolumn{4}{|c|}{ Untuk Madd dan Diftong } \\
\hline ص & $=$ & ș & $i=$ & $=$ & \multicolumn{2}{|c|}{$\bar{a}$ (a panjang) } \\
\hline 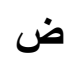 & $=$ & d & 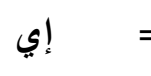 & $=$ & \multicolumn{2}{|c|}{$\overline{1}$ (i panjang) } \\
\hline b & $=$ & $t$ & 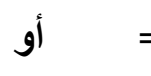 & $=$ & \multicolumn{2}{|c|}{$\bar{u}$ (u panjang) } \\
\hline ظ & $=$ & $z$ & او او & $=$ & \multicolumn{2}{|c|}{ aw } \\
\hline$\varepsilon$ & $=$ & 6 & أي اي & $=$ & \multicolumn{2}{|l|}{ ay } \\
\hline
\end{tabular}

Contoh penulisan dengan transliterasi:

اعوذ بالله من الشيطان الرجيم (a'üdhu bi al-Lāh min al-shaytān al-rajim);

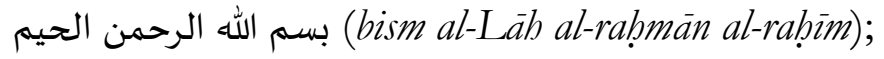

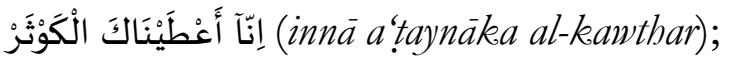

(fasalli lirabbika wanhar);

صباح الخير (șabāh al-khayr). 


\title{
MENCERNA AKAR FILSAFAT DALAM ISLAM
}

\author{
Ismail Fahmi Arrauf \\ (STAIN Zawiyah Cot Kala Langsa, Aceh \\ Email: ismailfahmiarraufnasution@yahoo.co.id)
}

Abstract. Philosophizing by philosophers is logical, independent, systematic, radical, and universal thinking on anything. Researchers have long been interested in investigating Islamic Philosophy, as a branch of science that develops later and commonly known as one rooted from Greece. This paper then aims at investigating the extent Islamic Philosophy interconnects with Greek Philosophy as well as their differences. Methods employed at this research are identifying Qur'an verses on Philosophy, and enriching them to reviews of related literature. Important findings are Islamic Philosophy is mainly derived from Qur'an values, its interconnectedness with Greek Philosophy does not mean it is integrated, and apart from different views on Philosophy, arguments where Qur'an reveals values of Philosophy is bighlighted.

Abstrak: Berfilsafat menurut filosof adalab berfikir logis, bebas, sistematis, radikal dan universal tentang apa saja yang ada. Filsafat Islam sebagai salah satu cabang ilmu yang berkembang kemudian hari, dikenal secara luas berasal dari Yunani. Filsafat yang penulis maksud dengan milik muslim adalah filsafat yang berakar dari Qur'an Hakim, buku sumber induk filsafat umat Islam, serta sunnah Nabi. Dinamakan Filsafat Islam bukan karena dibuat oleh orang Islam atau dibuat di negara Islam, melainkan karena inspirasinya, prinsip-prinsipnya dan halbal yang berkaitan dengannya diambil dari sumber al-Qur'an.

Keywords: Islam, filsafat, filsafat Islam, teologi, al-Qur'an. 
FILSAFAT Islam sebagai salah satu cabang ilmu yang berkembang kemudian hari, dikenal secara luas berasal dari Yunani. Bukan hanya penulis Barat ${ }^{1}$, tapi sebagian penulis muslim pun berpendapat sama, sehingga muncullah pernyataan bahwa ilmu pengetahuan yang berkembang di Barat sekarang, termasuk filsafat adalah berasal dari orang-orang Islam yang mereka ambil dari Yunani. Pendapat ini muncul berdasarkan pada kenyataan bahwa telah terjadi kegiatan penerjemahan bukubuku Yunani ke dalam bahasa Arab secara besar-besaran pada pertengahan abad ke delapan yang sebelumnya telah dimulai oleh Khalid bin Yazid. Meskipun Khalid hanya fokus pada karya-karya astrologi, kimia dan kedokteran, namun pada masa Abbasiyah, negara mengambil bagian yang aktif dalam penerjemahan tidak hanya terbatas pada buku-buku seperti yang disebut di atas tapi sudah menjangkau ruang lingkup yang lebih luas. ${ }^{2}$ Al-Ma'mun bahkan sengaja mencari karya filsafat Yunani untuk menjustifikasi kecenderungan rasionalitasnya dalam memahami teks-teks al-Qur'an. ${ }^{3}$

Meski fakta bahwa telah terjadi penerjemahan ilmu-ilmu karya Yunani ke dalam bahasa Arab adalah benar, namun untuk mengatakan bahwa filsafat Islam berasal dari Yunani tidaklah tepat, karena ternyata filsafat yang dihasilkan oleh filosof muslim berbeda dengan milik Yunani. Bagaimana mungkin sama pemikiran tentang Tuhan dan alam semesta, orang yang meyakini al-Qur'an dengan yang tidak. ${ }^{4}$ Oliver Leaman dalam

${ }^{1}$ Hitti menuliskan, "In essence their philosophy was Greek, modified by the thought of the conquered peoples and by other Eastern influences, adapted to the mental proclivities of Islam and expressed through the medium of Arabic." Lihat: P. K. Hitti, History of the Arabs (London: The Macmillan Press Ltd, 1970), 369.

${ }^{2}$ Majid Fakhry, Sejarah Filsafat Islam (Jakarta: Temprint, 1986), 20.

${ }^{3}$ Hitti, History of the Arabs..., 310.

${ }^{4} \mathrm{Nasr}$ menuliskan bahwa filsafat Islam bukanlah sekedar filsafat "Graeco-Alexandrian dalam jubah Arab", melainkan filsafat yang asli milik orang muslim yang berakar dari Quran dan Hadis. Lihat: Seyyed Hossein Nasr and Oliver Leaman, History of Islamic Philosophy (New York: Routledge, 2003), 27-37. Menurut Maurice de Wulf dalam bukunya Histoire de la Philosophie, penyelidikan filosof-filosof Islam tentang wujud lebih senang menyendiri dan tidak suka mengekor, karena berpegangan kepada Quran. Ahmad Hanafi, Pengantar Filsafat Islam, (Jakarta: Bulan Bintang, 1996), 16. 
An Introduction to Medieval Islamic Philosophy versi terjemahan Amin Abdullah, mengatakan dengan jelas, "Keliru besar kalau beranggapan bahwa filsafat Islam bermula dari penerjemahan teks-teks Yunani". 5 Majid Fakhry dalam Sejarah Filsafat Islam menuturkan bahwa penerjemahan naskah-naskah teologis yang kerapkali berkaitan dengan logika dilakukan bukan karena anggapan bahwa naskah tersebut baik isinya hingga layak dipelajari tapi karena dorongan kebutuhan untuk menyelidiki makna yang lebih dalam tentang konsep-konsep teologis dan proses dialektis yang sering muncul dalam perdebatan kristologis. ${ }^{6}$ Bahkan masih menurut Fakhry, para penerjemah itu tidak meneruskan terjemahan mereka sampai pada Isagoge Porphyry, Categories, Hermentica dan Analytica Priora, karena dianggap berbahaya mempelajari argumen-argumen yang demonstratif dan sofistis. ${ }^{7}$ Baru pada masa Al-Ma'mun bukubuku filsafat Yunani itu bisa diterjemahkan.

Filsafat yang penulis maksud dengan milik muslim adalah filsafat yang berakar dari Qur'an Hakim, buku sumber induk filsafat umat Islam, serta sunnah Nabi. Dinamakan filsafat Islam bukan karena dibuat oleh orang Islam atau dibuat di negara Islam, melainkan karena inspirasinya, prinsip-prinsipnya dan halhal yang berkaitan dengannya diambil dari sumber wahyu. Dalam bahasa Seyyed Hossein Nasr, "....Islamic philosophy, like everything else Islamic, is deeply rooted in the Qur'an and Hadits". ${ }^{8}$ Kebanyakan dari filosof Islam, kalau bukan seluruhnya, hidup dalam atmosfer Islam dan didominasi oleh realitas Qur'an dan Sunnah. Mereka hidup menurut hukum Islam dan beribadah sesuai dengan ajaran Islam. Bahkan sebagian mereka bukan hanya semata-mata filosof tapi juga ahli hukum, seperti Ibn Rushd, Shah Waliullah, Mir Damad, sehingga mereka cenderung berfilsafat ke arah yang lebih spesifik yang mungkin bisa disebut dengan "filsafat Nabi" (prophetic philosophy). ${ }^{9}$ Dalam khazanah Filsafat Islam, pengenalan model pengetahuan yang bersifat

5Oliver Leaman, Pengantar Filsafat Islam (Jakarta: Rajawali, 1989), 8.

${ }^{6}$ Fakhry, Sejarah Filsafat..., 28.

${ }^{7}$ Ibid.

${ }^{8} \mathrm{Nasr}$ and Leaman, History of Islamic..., 27.

I'Ibid., 28. 
rasional tidak berhenti dalam alur metodologi berpikir, melainkan berlanjut dalam pemaknaan spiritualitas. Makna spiritualitas hadir bersamaan dengan telaah reflektifkontemplatif. ${ }^{10}$

\section{Pengertian Filsafat Secara Etimologi}

Istilah filsafat, menurut Ahmad Tafsir dalam Amsal Bakhtiar, berasal dari bahasa Yunani yang terdiri atas dua kata: philo dan sophia. Philo berarti cinta dalam arti luas, yakni keinginan dan sophia berarti hikmah (kebijakan) atau kebenaran. Jadi secara etimologi, filsafat berarti cinta kebijakan atau kebenaran. ${ }^{11}$

Harun Nasution berpendapat bahwa kata filsafat berasal dari bahasa Arab falsafa. ${ }^{12}$ Muhaimin juga berpendapat bahwa filsafat berasal dari bahasa Arab falsafah. Menurutnya, orang Arab mengambilnya dari bahasa Yunani philosophia yang artinya ingin mengerti dengan mendalam atau cinta kebijaksanaan. ${ }^{13}$

Menurut versi lain, filsafat diambil dari bahasa Yunani philosophus. Kata ini dipakai pertama kali oleh Socrates, pemikir paling masyhur yang menyanggah dan menentang kaum sofis. ${ }^{14}$ Socrates menamakan dirinya philosophus, pecinta kebijaksanaan. Ungkapan ini lantas di-Arab-kan menjadi failasuf dan dari situ pula kata falsafah diambil.

${ }^{10}$ Musa Asy'arie, Filsafat Islam (Yogyakarta: LESFI, 1999), 71.
${ }^{11}$ Amsal Bakhtiar, Filsafat Agama (Jakarta: Logos Wacana Ilmu, 1999), 6.
${ }^{12}$ Harun Nasution, Filsafat Agama (Jakarta: Bulan Bintang, 1991), 3.
${ }^{13}$ Muhaimin, Kawasan dan Wawasan Studi Islam (Jakarta: Kencana, 2005), 303.

${ }^{14}$ Sofis dalam bahasa Yunani artinya orang bijak atau berilmu. Kaum sofis yang dimaksud adalah sekelompok sarjana pengajar professional dalam seni retorika dan debat. Pekerjaan mereka adalah melatih para pengacara untuk terampil debat di pengadilan. Bergumul dengan pengajaran yang seringkali tercemar dengan kerancuan berfikir membuat mereka menolak mentah-mentah kebenaran di luar pikiran manusia. Socrates memakai nama philosophus untuk menunjukkan kerendahan hatinya, sekaligus menyindir para sofis, seolah dia berkata pada mereka, "Kalian yang bergelut dalam keilmuan demi tujuan materi dan politik tidaklah layak menyandang gelar sofis (orang bijak). Bahkan saya yang menolak gagasan anda dengan alasan yang jauh lebih kuat, merasa tidak layak menyandang gelar itu, dan lebih memilih nama pecinta kebijaksanaan". Lihat: Muhammad Taqi Mishbah Yazdi, Buku Daras Filsafat Islam, versi terjemahan Indonesia, (Bandung: Mizan, 2003), 4-5. 
Padanan kata falsafah adalah hikmah yang artinya pintar dalam masalah-masalah ilmiah. ${ }^{15}$ Dengan demikian, bikmah adalah perkara tertinggi yang bisa dicapai oleh manusia dengan melalui alat-alat tertentu, yaitu akal dan metode-metode berpikirnya.

\section{Terminologi Filsafat}

Pengertian filsafat sangat beragam, baik dalam ungkapan maupun titik tekannya. Sebagian pakar merasa tidak perlu definisi filsafat diberikan mengingat setiap orang mempunyai titik tekan sendiri dalam pemberian definisi tersebut. Oleh karenanya, Moh. Hatta mengatakan, lebih tepat bila orang meneliti filsafat terlebih dahulu baru kemudian menyimpulkannya sendiri. Kendati pun demikian penulis merasa perlu untuk mengetahui pengertian filsafat oleh para filosof sendiri walaupun penekanannya berbeda-beda, agar bisa dilihat secara keseluruhan dan dapat dipahami garis besarnya.

Plato mengatakan bahwa filsafat adalah pengetahuan tentang segala yang ada, dengan mencintai kebenaran serta penyelidikan, dan lebih mengutamakan jalan keyakinan daripada dugaan. Sementara Aristoteles mengatakan bahwa filsafat adalah menyelidiki sebab dan azas segala benda. Itulah sebabnya kenapa Aristoteles menamakan filsafat dengan "teologi" atau "filsafat pertama" yang membawanya pada kesimpulan bahwa setiap gerak di alam ini digerakkan oleh yang lain. Maka perlu menetapkan penggerak yang menyebabkan gerak tersebut. Penggerak tidak ikut bergerak dengan yang lain karena dia terlepas dari materi, kalau dia bermateri maka ia juga berpotensi untuk bergerak. Demikianlah Aristoteles menemukan tuhan yang ia sebut Aktus Murni. ${ }^{16}$

Al-Kindi meninjau filsafat dari dalam dan dari luar. Menurutnya filsafat adalah ilmu tentang hakikat (kebenaran) sesuatu menurut kesanggupan manusia yang mencakupi ilmu ketuhanan, keesaan, keutamaan dan ilmu tentang yang berguna sekaligus cara memperolehnya serta ilmu cara menjauhi hal-hal yang merugikan. Itu lah yang beliau maksud dengan filsafat yang

15Lois Ma'luf, Al-Munjid fĩ al-Lugah wa al-A'lam (Beirut: Dar el-Machreq, 1986), 593.

${ }^{16}$ Bakhtiar, Filsafat Agama..., 8. 
bersifat teori. Sedangkan filsafat yang bersifat amalan adalah mewujudkan kebenaran yang kita ketahui atau kita temukan tersebut dalam tindakan. ${ }^{17}$

Filsafat menurut al-Farabi adalah pengetahuan tentang alam yang maujud dan bertujuan menyelidiki hakikat yang sebenarnya, sementara Immanuel Kant, tokoh filosof modern berpendapat bahwa filsafat adalah pengetahuan mengenai pokok pangkal dari segala pengetahuan dan perbuatan. N. Driyakara dengan ungkapan yang menarik mengatakan bahwa filsafat adalah permenungan yang sedalam-dalamnya tentang sebab-sebab "ada" dan "berbuat". Permenungan tentang kenyataan yang sedalam-dalamnya, sampai "mengapa" yang penghabisan. ${ }^{18}$

Seorang filosof dari Timur, Fung Yu Lan, mengatakan bahwa filsafat adalah pikiran yang sistematis dan refleksi tentang hidup. Sementara itu, Harun Nasution mengatakan bahwa filsafat adalah berpikir menurut tata tertib (logika) dengan bebas (tidak terikat tradisi, dogma dan agama) dan dengan sedalamdalamnya, sehingga sampai pada dasar-dasar persoalan. ${ }^{19}$

Menurut Endang Saifuddin Anshari, filsafat adalah hasil usaha manusia dengan kekuatan akal budinya untuk memahami secara radikal, integral, dan universal hakikat sarwa yang ada (Tuhan, alam, dan manusia), serta sikap manusia termasuk sebagai konsekuensi dari pahamnya tersebut. ${ }^{20}$

Kendatipun defenisi-defenisi di atas berbeda-beda, terdapat persamaan yang cukup jelas yang merupakan unsur-unsur dasar filsafat. Kesimpulan dari persamaan tersebut adalah bahwa filsafat membahas tentang realitas secara radikal (mengakar), sistematis, bebas, dan universal.

Adapun pembagian ilmu filsafat menurut Muhaimin adalah sebagai berikut:

1. Metafisika, yaitu filsafat tentang hakikat yang bersifat transenden, di luar batas nalar manusia.

${ }^{17}$ Ahmad Hanafi, Pengantar Filsafat Islam (Jakarta: Bulan Bintang, 1996), 74.

${ }^{18}$ Bakhtiar, Filsafat Agama..., 8.

${ }^{19}$ Ibid., 9.

${ }^{20}$ Muhaimin, Kawasan dan Wawasan..., 305. 
2. Logika, yaitu filsafat tentang pikiran yang benar dan salah.

3. Etika, tentang tingkah laku yang baik dan buruk.

4. Estetika, tentang seni dan keindahan

5. Epistemologi, tentang ilmu pengetahuan

6. Filsafat-filsafat khusus, seperti filsafat alam, filsafat agama dll. 21

\section{Filsafat dan Teologi}

Intelektual muslim sepakat bahwa kekuatan akal atau rasio sangat dibutuhkan dalam kajian agama, karena bagaimana pun untuk memahami teks agama yang jelas maknanya saja dibutuhkan kekuatan rasio, apalagi untuk memahami teks yang memungkinkan untuk ditafsirkan berbeda-beda. Hanya saja, sejauh mana rasio bisa digunakan dalam memahami kajian-kajian agama, masih menjadi hal yang kontroversial. Sebagian beranggapan rasio mesti dipakai setelah wahyu, apabila tidak ada wahyu tentang masalah tertentu barulah rasio digunakan untuk memecahkan masalah tersebut. Sebagian lagi beranggapan bahwa rasio saja sudah cukup untuk membimbing manusia pada kebenaran, wahyu hanya sebagai justifikasi atas apa yang telah ditemukan rasio. Dalam ranah kajian agama Islam para mutakallimin (teolog) dan filosof yang cenderung mengedepankan rasio.

Teologi dan filsafat sesungguhnya sama-sama menggunakan metode silogisme dalam cara berpikirnya. Silogisme adalah suatu metode pengambilan kesimpulan berdasarkan premis mayor dan premis minor. Namun demikian terdapat perbedaan sumber pengambilan kesimpulan dalam filsafat dan teologi. Di dalam filsafat, premis mayor adalah premis yang telah teruji secara rasional sehingga sifatnya meyakinkan melalui rasio, sementara dalam teologi premis mayor diambil dari sesuatu yang sudah diyakini secara umum seperti wahyu dan doktrin agama. ${ }^{22}$ Filosof berangkat dari keraguan sehingga melakukan pencarian secara rasional untuk mendapatkan kebenaran final. Sedangkan

${ }^{21}$ Ibid,

${ }^{22}$ A. Khudori Soleh, Wacana Baru Filsafat Islam (Yogyakarta: Pustaka Pelajar, 2004), 20-7. 
Teolog berangkat dari kebenaran yang didapatnya dari wahyu kemudian mencari argumen yang rasional untuk membuktikan kebenaran tersebut.

Teologi muncul sebagai sebuah sistem berpikir rasional untuk meng-counter pemikiran rasional bebas yang menyerang otoritas wahyu. Teologi lahir jauh sebelum masa penerjemahan buku-buku filsafat Yunani oleh Al-Ma'mun. Justru teologi, karena mempunyai persamaan dengan filsafat ${ }^{23}$ tanpa sadar telah menyiapkan landasan bagi berkembangnya filsafat Yunani. Meski menjadi landasan tumbuhnya filsafat, hubungan keduanya tak selalu harmonis. Sering terjadi perdebatan antara teolog dengan filosof seperti Abu Sa'id al-Shirafi ${ }^{24}$ dengan Abu Bishr Matta $^{25}$. Ketegangan semakin meruncing setelah al-Farabi menempatkan teologi dan fiqh pada ranking bawah setelah ilmuilmu filsafat. ${ }^{26}$

Tahäfut al-Faläsifah dan al-Munqidh min al-Daläl adalah karya al-Gazālī yang berisikan penyerangan terhadap filsafat, sungguhpun dia sendiri adalah filosof, meskipun ada yang menggolongkannya ke dalam teolog, namun dia memulainya dengan filsafat (dan berakhir dalam sufisme). Dalam karyanya tersebut dia menyerang lapangan filsafat metafisika. Tak hanya al-Gazālī, namun sejumlah teolog dari ahlussunnah banyak yang menyerang filsafat, seperti Ibn Hazm, Ibn Taimiyah, dan Ibn alQayyim. Untuk melihat gambaran ketegangan teologi dan filsafat rasanya perlu penulis mengutip fatwa Ibn al-Ṣalāh yang sering didengungkan oleh Kubra Zadah:

Filsafat adalah pokok kebodohan dan penyelewengan, bahkan kebingungan dan kesesatan. Siapa yang berfilsafat, maka butalah hatinya dari kebaikan-kebaikan syariat yang suci, yang dikuatkan dengan dalildalil yang lahir dan bukti-bukti yang jelas. Barangsiapa yang mempelajarinya, maka ia bertemankan kehinaan, tertutup dari kebenaran dan terbujuk oleh setan. Apakah ada ilmu lain yang lebih

${ }^{23}$ Teologi dan filsafat mempunyai objek bahasan yang sama dan samasama memberikan argument yang rasional. Lihat, Bakhtiar, Filsafat Agama..., 23.

${ }^{24}$ Seorang teolog Mu'tazilah lahir tahun $893 \mathrm{M}$ dan wafat tahun $979 \mathrm{M}$.

${ }^{25}$ Guru filsafat Farabi yang beraliran Nestorian, lahir $870 \mathrm{M}$ dan wafat $940 \mathrm{M}$.

${ }^{26}$ Soleh, Wacana Baru..., 25. 
hina dari ilmu yang membutakan orang yang memilikinya dan menggelapkan hatinya dari sinar kenabian Nabi kita. ${ }^{27}$

Meskipun ada ketegangan antara filsafat dan teologi, tidak berarti semua teolog bersikap sama terhadap filsafat. Sebagian ada yang membela kebebasan berpikir dan lebih mengandalkan rasio sehingga bisa menerima usaha filsafat untuk menemukan kebenaran. Sebagian lagi menolak filsafat mentah-mentah.

Namun perlu dicatat bahwa keberatan teolog terhadap filsafat kebanyakan lebih kepada teori mereka tentang Tuhan atau terbatas hanya pada filsafat metafisika. Karya Ibn Taimiyah "al-Raddu 'alā al-Mantiqiyyin", sungguh pun mantiq itu adalah logika, namun yang dikritik Ibn Taimiyah sebenarnya adalah pemahaman Ilahiah para pemakai logika (filosof), bukan logika itu sendiri. Beliau mengakui bahwa sebagian filsafat benar dan sebagian kafir, seperti yang ditulisnya dalam bukunya "Majmù' alFatāw $\vec{a} .28$

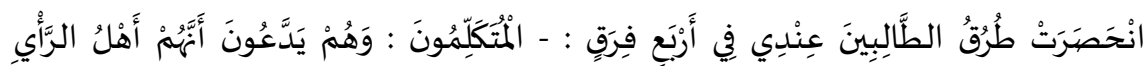

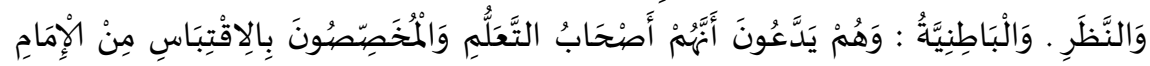

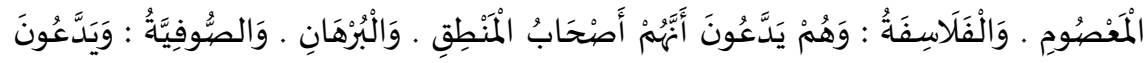

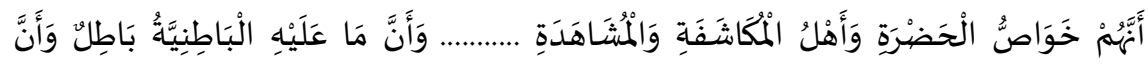

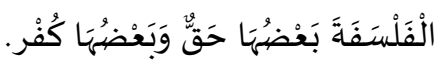

Al-Gazālī pun sebenarnya tidak menyerang filsafat Ibn Sina secara keseluruhan, melainkan hanya pada metafisika saja. Justru dia menyayangkan adanya sikap penolakan terhadap filsafat secara keseluruhan, perasaan ini ia nyatakan dalam bukunya alMunqidh min al-Ḍalàl. Menurutnya, bila umat Islam meninggalkan Logika, Etika, Matematika dan ilmu filsafat lainnya, ini akan melemahkan umat Islam dan membahayakannya. Al-Gazālī, dalam Tahäfut al-Falāsifah, sebenarnya hanya menyerang paham Ibn Sina tentang 3 hal, yang menurutnya dipengaruhi Aristoteles; 1) Manusia tidak dibangkitkan secara jasmaniah namun hanya rohaninya saja. Pada hari kiamat manusia hanya dihukum secara

${ }^{27}$ Hanafi, Pengantar Filsafat..., 20.

${ }^{28}$ Ibn Taimiyah, Majmū' al-Fatāwā Juz 2, Cet. III, (Dār al-Wafa', 2005), 55. 
spiritual bukan jasmani; 2) Tuhan hanya mengetahui hal-hal yang universal dan tidak yang partikular; 3) Dunia ini kekal. ${ }^{29}$

\section{Filsafat dalam al-Qur'an}

Agama Islam memberikan penghargaan yang sangat tinggi terhadap akal dengan banyaknya ayat-ayat al-Qur'an yang menganjurkan manusia supaya banyak berpikir, menggunakan akalnya untuk mengupas rahasia alam, mencari kebenaran dan mempelajari ciptaan-Nya.

Di dalam al-Qur'an terdapat 49 kali perkataan yang berakar dari kata 'aql (akal) dan semuanya dalam bentuk kata kerja aktif seperti táqilüna, na'qilu, ya'qilūna, ya'qilubā. Bukan hanya akal yang menunjukkan pekerjaan berpikir tapi juga istilah-istilah lain seperti naz̧ara (melihat dengan abstrak dalam arti merenung), tadabbara (merenung), tafakkara, faqiha, tadhakkara (mengingat atau mendapat pelajaran). Di samping itu, di dalam al-Qur'an juga banyak sebutan-sebutan yang memberi sifat berpikir seperti, ùlù al-bāb, ùlù al-ìlmi, ùlù al-abșār, ùlù al-nubāa. Kesemuanya mengandung anjuran dan dorongan agar manusia banyak berpikir dan menggunakan akalnya. Dengan kata lain, Allah melalui firman-firman-Nya di dalam al-Qur'an mendorong bahkan memerintahkan manusia agar berfilsafat. ${ }^{30}$

Anjuran Tuhan seperti yang telah dijelaskan di atas bukan hanya tergambar dalam pemakaian kata-kata yang berakar pada 'aql dan yang mengandung arti berpikir saja, tapi bahkan banyak ayat yang terkandung di dalam al-Qur'an sendiri filosofis, membutuhkan rasio untuk memahaminya sehingga Tuhan sendiri meletakkan filsafat (hikmah) sejajar dengan "kitab".

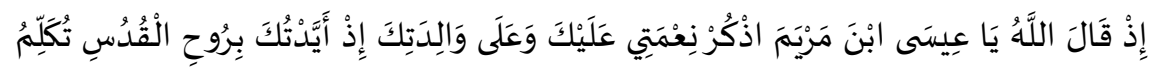

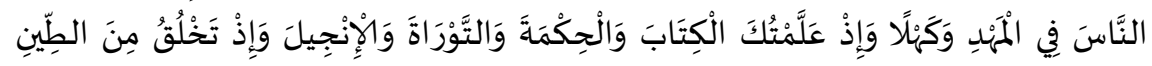

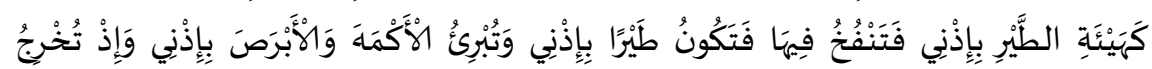

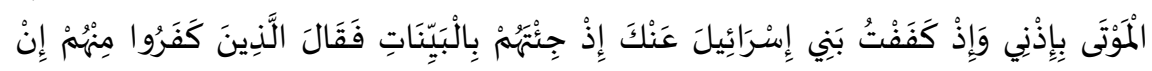

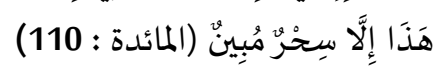

${ }^{29}$ Leaman, Pengantar Filsafat..., 29.

${ }^{30}$ Muhaimin, Kawasan dan Wawasan..., 306. 


\section{Hikmah Sebagai Padanan Filsafat}

Sebagaimana telah disebutkan bahwa kata filsafat di dalam Al-Munjid fi al-Lugah wa al-A'lam mempunyai sinonim b̧ikmah. Sebelumnya kata ini dipakai pertama sekali sebagai padanan filsafat oleh al-Kindi yang biasa menuliskan padanan Arab untuk istilah-istilah dalam filsafat Yunani. ${ }^{31}$ Beberapa penulis kontemporer pun telah memaknai bikmah sebagai filsafat. Namun penulis ingin mundur sedikit untuk meninjau kembali makna hikmah secara umum, khususnya kata hikmah di dalam alQur'an menurut ahli tafsir.

Terma ḩikmah terulang sebanyak dua puluh kali dalam dua belas surat di dalam al-Qur'an. Dalam kitab-kitab tafsir klasik tidak satu pun dari dua puluh kata hikmah tersebut yang diartikan dengan filsafat, bahkan Quraish Shihab, mufassir kontemporer pun tidak memaknainya dengan filsafat. Menurut beliau, hikmah akar katanya ḩakama, maknanya menghalangi. Jadi, sesuatu yang bila digunakan akan menghalangi terjadinya mudarat atau kesulitan dan mendatangkan kemaslahatan. Lebih jauh beliau mengatakan bahwa hikmah juga berarti mengetahui yang paling utama dari segala sesuatu, baik yang berkaitan dengan ide, maupun perbuatan. Memilih perbuatan yang terbaik dan sesuai adalah perwujudan dari hikmah. Memilih yang terbaik dari dua hal pun disebut dengan ḩikmah, pelakunya disebut dengan hăkim. Demikian pula menurut pandangan Imām al-Gazālī, ḩikmah berarti pengetahuan tentang sesuatu yang paling utama. ${ }^{32}$

Menurut al-Ṭabari dalam tafsirnya, hikmah artinya benar dalam berkata dan berbuat. Menurut Ibnu Abbas, hikmah adalah pengetahuan tentang al-Qur'an, yaitu; nāsikh mansukhnya, mublkamāt dan mutashäbihätnya, tentang mana yang harus didahulukan dan mana yang diakhirkan, tentang halal dan haram dan semisalnya. ${ }^{33}$

Sedangkan Ibnu 'Adil dalam kitab Tafsir al-Lubab, mengartikan bikmah dengan nubuwwah (kenabian). Sementara

${ }^{31}$ Hanafi, Pengantar Filsafat..., 79 .

${ }^{32}$ M. Quraish Shihab, Ensiklopedia al-Qur'an: Kajian Kosa Kata (Jakarta: Lentera Hati, 2007), 272-4.

${ }^{33} \mathrm{Abū}$ Ja'far al-Ṭabari, Jamì' al-Bayān fì Ta'mūl al-Qur'ān, jilid 5 (Muassasah al-Risālah, 2000), 576. 
Muqatil dalam Mafätị̧ al-Gaib karya al-Rāzi mengatakan bahwa bikmah di dalam al-Qur'an mempunyai empat arti; mawä'za alQur'an, al-fahm wa al-ilm (paham dan ilmu), al-nubuwwah (kenabian), al-Qur'an bi mā fïhi min 'ajäib al-asrär (al-Qur'an beserta rahasia-rahasia gaib yang ada di dalamnya):

تفسير الحكمة في القرآن على أربعة أوجه أحدها : مواعظ القرآن، قال في البقرة ( وَمَا أَنزلَّل

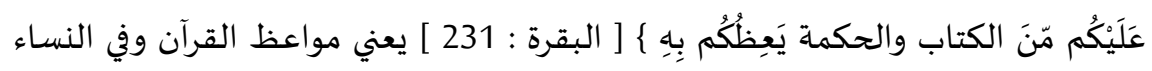

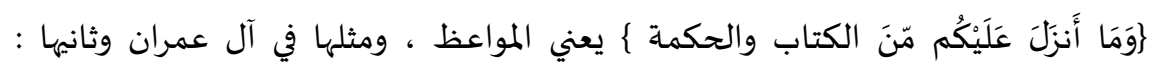

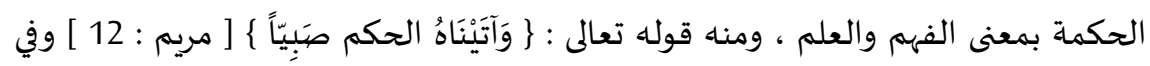

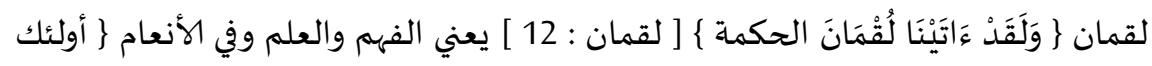

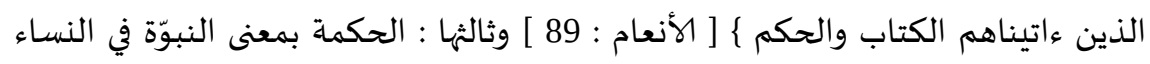

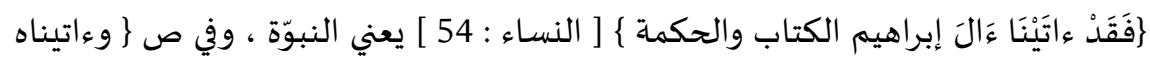

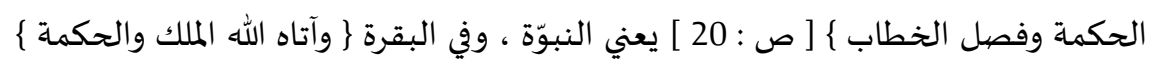

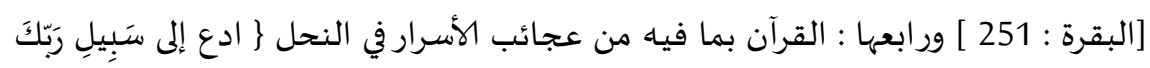

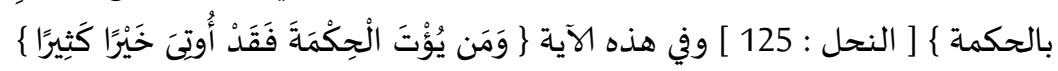

Ṭabațabai memaknai hikmah dengan kearifan ${ }^{34}$, sedangkan Qatādah mangartikannya dengan sunnah, alasannya yaitu bahwa kata hikmah didampingkan dengan kitāb yang bermakna alQur'an, maka dampingan yang pantas bagi al-Qur'an tiada lain adalah sunnah.

Meski tidak ada pengertian yang jelas yang mengatakan bahwa bikmah adalah filsafat, namun dari arti-arti yang telah diberikan oleh para mufassir tersebut dapat diketahui bahwa bikmah sama dengan falsafah. Sama-sama mendatangkan maslahah dan menghindari mudārat, sama-sama untuk mengetahui yang baik dan yang buruk, dan sama-sama berarti ilmu dan paham tentang segala sesuatu. Filosof dan băkim adalah sama-sama berarti orang arif dan bijaksana.

\section{Ajaran Filosofis al-Qur'an}

Meskipun bukan al-Qur'an satu-satunya kitab suci yang diturunkan Tuhan, namun umat Islam hanya berpegang pada

${ }^{34}$ Allamah Sayid M. Husain Ṭabațaba'i, Tafsìr al-Mižān (Jakarta: Lentera, 2010), 128. 
syariat yang ada dalam al-Qur'an, dengan tetap berkeyakinan bahwa kitab Zabur, Taurat dan Injil juga kitab suci dari Tuhan. Doktrin yang dibawa kitab sebelumnya sama dengan doktrin yang ada dalam al-Qur'an, begitu juga uraian fakta-fakta sejarah, tidak ada yang berubah. Tuhan tidak menghapus atau melupakan wahyu yang datang sebelumnya, hanya saja, perbedaan waktu membutuhkan penyesuaian dalam penentuan hukum-hukum (syariat) sehingga dalam al-Qur'an ada penegasan tentang hukum lama, atau menggantinya dengan sesuatu yang serupa atau yang lebih baik. ${ }^{35}$

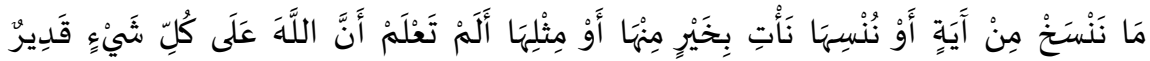

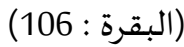

Al-Qur'an disebut juga dengan nama lainnya al-ḥakimdiambil dari kata yang sama dengan b̧ikmah, ḩakama-adalah kitab suci, bukan kitab filsafat, berisikan wahyu-wahyu Tuhan yang kebenarannya pasti, namun membahas hal-hal yang berkaitan dengan filsafat atau tepatnya hal-hal yang juga dipikirkan oleh filosof seperti Tuhan, alam, jiwa, inter-relasi antara baik dan buruk, kebebasan berkehendak, dan kehidupan setelah mati. Selain itu al-Qur'an juga berbicara tentang konsepkonsep; shubud, realita, wujud, manusia, takdir, ruang, waktu, dan kekal. ${ }^{36}$

Telah diterangkan sebelumnya bahwa banyak ayat yang terkandung di dalam al-Qur'an ternyata filosofis, membutuhkan rasio untuk memahaminya sehingga wajar saja filsafat (bikmah) sejajar dengan "kitab", karena untuk dapat memahami al-Qur'an dibutuhkan "hikmah", yaitu ilmu atau pemahaman tentang ayatayat (red: tanda-tanda), agar mendapatkan kebenaran yang sesungguhnya, mendatangkan maslahah dan terhindar dari mudārat. Misalnya, untuk mengetahui makna 6 hari dalam firman Tuhan tentang penciptaan langit dan bumi dibutuhkan kemampuan menggunakan ḩikmah.

${ }^{35} \mathrm{MM}$ Sharif, A History of Muslim Philosophy, volume I (Delhi: Adam Publisher, 2001), 136.

${ }^{36}$ Ibid. 


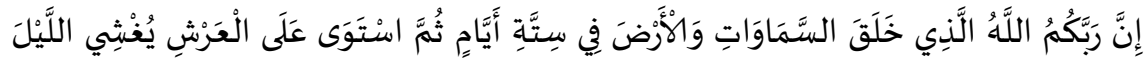

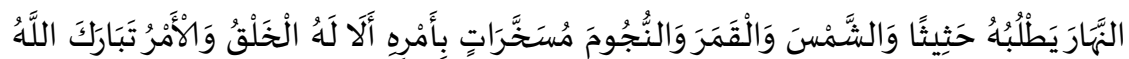

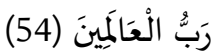

Ayat di atas mengundang banyak pertanyaan. Apa arti 6 hari? Apakah hari di situ bermakna tahap? Ataukah hari yang dimaksud adalah Ahad, Senin, Selasa, Rabu, Kamis dan Jumat?, Kenapa Tuhan menciptakan langit dan bumi harus bertahap? Apakah Dia tidak mampu untuk menciptakannya sekali jadi?. Begitulah, banyak terdapat ayat-ayat di dalam al-Quran yang mengundang banyak pertanyaan yang jawabannya membutuhkan pengetahuan dan pemahaman yang dihasilkan dari proses berpikir.

\section{Filsafat/Hikmah sebagai sunnah Nabi}

Nabi Muhammad saw., sejak kecil dikenal sangat cerdas. Ketika ikut berdagang ke Syam bersama Abu Thalib ia bertanya pada pamannya tentang hakikat penciptaan alam. Sebagai pemuda yang cerdas dan kritis, beliau telah mempunyai sifat-sifat yang menunjukkan kualitas seorang filosof. Oleh karena kecerdasan dan sifat-sifat yang dimilikinya beliau dapat menyelesaikan pertikaian pemuka Quraish dalam memperebutkan siapa yang harus meletakkan Hajar Aswad ke tempatnya semula.

Melihat realitas sosial yang bobrok, sebagai seorang warga yang berkepribadian unggul, beliau merasa sangat gelisah. Kegelisahannya mendorongnya pergi mencari pencerahan ke Gua Hira. Beliau pergi untuk merenungkan dan memikirkan apa sebab semua itu terjadi dan bagaimana cara mengatasinya. Sampai akhirnya turunlah wahyu pertama, yaitu perintah untuk "membaca". Membaca di sini bisa diartikan dengan membaca realitas sosial yang ada dalam kehidupan masyarakatnya, dengan didasari oleh adanya kesadaran yang transendental. Membaca realitas sosial membutuhkan kemampuan konseptual guna memahami dinamika masyarakat. Kemampuan tersebut berkaitan dengan kecerdasan yang dimiliki beliau. ${ }^{37}$ Dengan kata

${ }^{37}$ Asy'arie, Filsafat Islam..., 10-3 . 
lain, sebenarnya Tuhan memerintahkan Nabi untuk menggunakan potensi akalnya membaca gejala sosial yang ada pada masyarakatnya dan kemudian memikirkan jalan keluar untuk mengatasinya. Dan semuanya itu harus disertai dengan kesadaran bahwa itu dilakukan karena Tuhan.

Setelah menjadi rasul, beliau ditanya tetang teori emanasi, maka beliau menjawab:

$$
\text { كان الله و لم يكن شيء غيره و كتب في الذكر كل شيء ثم خلق السموات و الأرض }
$$

Contoh lain adalah pada peristiwa Fathu Makkah, nabi menganjurkan untuk beristirahat di suatu tempat, namun seorang sahabat bertanya, apakah anjuran itu wahyu dari Tuhan atau hasil pemikiran Nabi, beliau menjawab bahwa itu adalah pemikirannya saja bukan wahyu. Akhirnya atas anjuran sahabat tersebut pasukan muslim beristirahat di daerah oase.

Jika dilihat dari fakta sejarah, apa yang dilakukan oleh Nabi sebenarnya merupakan penjelmaan dari tugas seorang filosof sejati, setidaknya, sebelum beliau diangkat menjadi rasul, beliau sudah memiliki kulitas seorang filosof. Hal ini bersesuaian dengan pendapat al-Syahrastani tentang nabi. Menurutnya seorang nabi harus memiliki semua kualitas alamiah pada derajat tertinggi, termasuk kualitas intelektual. Nabi harus memiliki watak yang utama, sifat selalu benar dan jujur sebelum ditunjuk sebagai nabi. Allah juga telah mengatakan dalam firman-Nya dalam Qs. al-Māidah (5):89, bahwa Dia telah memberikan bikmah kepada para nabi.

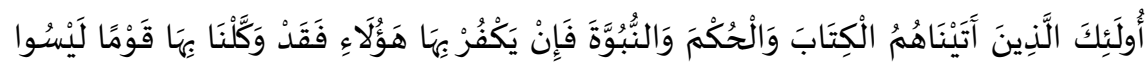

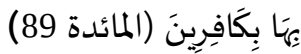

Dalam buku tafsir Jalalain, al-hukm di dalam ayat ini maksudnya adalah hikmah. Al-Bayḍāwī di dalam tafsirnya kurang lebih menyatakan hal yang sama yaitu:

$$
\text { الحكمة أو فصل الأمر على ما يقتضيه الحق } 38
$$

Sehingga para nabi dan orang-orang yang diberi ḅikmah (filosof) adalah termasuk dalam golongan orang-orang yang

${ }^{38}$ Al-Bayḍāwī, Tafsìr Al-Baydāwì, jilid 1, 428. 
mendapatkan kebaikan yang banyak karena menggunakan akal pikiran mereka. Sebagaimana disebutkan dalam firman Allah dalam Qs. al-Baqarah (2): 269 sebagai berikut:

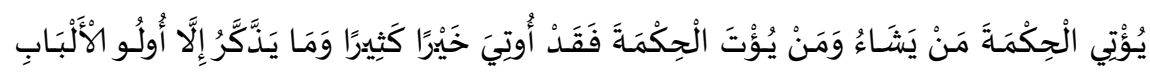

Dengan begitu, setiap nabi sebenarnya adalah juga seorang filosof, namun tidak sebaliknya, tidak semua filosof adalah nabi. Sebagai seorang nabi yang menerima wahyu, apa yang disampaikan rasul adalah mutlak benar karena itu berasal dari Tuhan Yang Maha Benar. Sedangkan sebagai seorang filosof, hasil pemikirannya belum tentu benar karena kebenaran filsafat sifatnya spekulatif.

\section{Catatan Akhir}

Setelah membaca uraian di atas dapatlah dipahami bahwa filsafat menurut filosof adalah berpikir logis, bebas, sistematis, radikal dan universal tentang apa saja yang ada. Karena sifatnya yang bebas dari dogma dan agama, para teolog menolak seluruh cara filsafat, menganggapnya sesat dan tidak Islami. Tapi sebagian teolog tidak menolak seluruhnya, melainkan hanya menolak yang berkaitan dengan metafisika saja. Sementara mufassir meyakini bahwa ayat-ayat al-Qur'an mengandung anjuran dan perintah untuk berpikir, yang kemudian diartikan sebagai berfilsafat.

Di antara filosof, teolog, dan sufi, terminologi hikmah telah sering dipakai untuk menyebutkan filsafat Islam, namun tak seorang mufassir klasik pun yang mengartikannya dengan filsafat. Sungguhpun begitu, arti hikmah yang diberikan oleh mufassir, menurut hemat penulis tidak berbeda dengan filsafat. Bila dimaknai dengan kendali yang menghindarkan dari mudarat dan mendekatkan pada maslahat, maka itu sejalan dengan makna filsafat yaitu mencari kebenaran. Kalau sudah berjalan di atas kebenaran tentu akan terhindar dari mudarat dan mendapatkan maslahat. Begitu juga makna-makna lainnya; benar dalam perkataan dan perbuatan, pengetahuan tentang yang benar, pemahaman, kearifan, pengetahuan tentang rahasia-rahasia tentang yang ghaib dalam al-Quran. Bahkan bila dimaknai 
dengan al-Qur'an pun, masih sejalan dengan filsafat karena alQur'an yang disebut dengan al-Häkim (diambil dari kata hakama, akar kata yang sama dengan hikmah) itu pun menganjurkan berfilsafat dan kandungannya banyak memuat masalah-masalah yang menjadi bahasan filsafat. 'Ala kulli hal, haqq al-yaqin bahwa filsafat dalam Islam berakar dari al-Qur'an dan Sunnah. Wa alLäh a lam bi al-sawāh.•

\section{Daftar Pustaka}

Asy'arie, Musa. 1999. Filsafat Islam. Yogyakarta: LESFI.

Al-Bayḍāwī, Tafsì Baidowi, jilid 1.

Bakhtiar, Amsal. 1999. Filsafat Agama. Jakarta: Logos Wacana Ilmu.

Fakhry, Majid. 1986. Sejarah Filsafat Islam. Jakarta: Temprint. Hanafi, Ahmad. 1996. Pengantar Filsafat Islam. Jakarta: Bulan Bintang.

Hitti, P. K. 1970. History of the Arabs. London: The Macmillan Press Ltd.

Leaman, Oliver. 1989. Pengantar Filsafat islam. Jakarta: Rajawali.

Ma'luf, Lois. 1986. Al-Munjid fi al-Lugah wa al-A'lam. Beirut: Dar el-Machreq.

Muhaimin. et al. 2005. Kawasan dan Wawasan Studi Islam. Jakarta: Kencana.

Nasr, Seyyed Hossein and Oliver Leaman. 2003. History of Islamic Philosophy, New York: Routledge.

Nasution, Harun. 1991. Filsafat Agama. Jakarta: Bulan Bintang. Sharif, MM. 2001. A History of Muslim Philosophy. volume 1. Delhi: Adam Publisher.

Shihab, M. Quraish. 2007. Ensiklopedia Al-Quran: Kajian Kosa Kata. Jakarta: Lentera Hati.

Soleh, A. Khudori. 2004. Wacana Baru Filsafat Islam. Yogyakarta: Pustaka Pelajar.

Taimiyah, Ibnu. 2005. Majmu' al-Fatāwa Juz 2. Cet. III. Dār alWafa'.

Ṭabatțaba'i, 'Allāmah Sayyid M. Husain. 2010. Tafsìr al-Mì̄ān. Jakarta: Lentera. 
Al-Ṭabari, Abū Ja'far. 2000. Jamì' al-Bayān fì Ta'mūl al-Qur'ān. jilid 5. Muassasah al-Risālah.

Yazdi, Muhammad Taqi Mishbah. 2003. Buku Daras Filsafat Islam. versi terjemahan Indonesia. Bandung: Mizan. 